\title{
Hand grip endurance test relates to clinical state and prognosis in COPD patients better than 6-minute walk test distance
}

This article was published in the following Dove Press journal: International Journal of COPD

\author{
Miroslav Kovarik ${ }^{1,2}$ \\ Vera Joskova ${ }^{1,2}$ \\ Anna Patkoval,2 \\ Vladimir Koblizek ${ }^{3}$ \\ Zdenek Zadak ${ }^{2}$ \\ Miloslav Hronek ${ }^{1,2}$ \\ 'Department of Biological and Medical \\ Sciences, Faculty of Pharmacy in \\ Hradec Kralove, Charles University, \\ Hradec Kralove, Czech Republic; \\ 2Department of Research and \\ Development, University Hospital \\ Hradec Kralove, Hradec Kralove, \\ Czech Republic; ${ }^{3}$ Department of \\ Pulmonary Medicine, University \\ Hospital Hradec Kralove, Hradec \\ Kralove, Czech Republic
}

Purpose: Patients with COPD present peripheral muscle dysfunction and atrophy, expressed as muscle strength and endurance reduction. The goal of this study was direct dynamometric assessment of hand grip endurance and strength in relation to the stage of disease, multidimensional predictors of mortality, and 6-minute walk test (6MWT). To the best of our knowledge, there has been no previous study determining these parameters.

Patients and methods: In this observational study, 58 consecutive outpatients with stable COPD and 25 volunteers without respiratory problems were compared. All COPD subjects underwent a comprehensive examination to determine COPD severity, prognostic scales, and 6MWT. Body composition, basic spirometric parameters, and hand grip strength and endurance were determined in all study participants.

Results: Patients in the COPD group had a $15 \%$ decrease in maximum strength $(P=0.012)$ and a $28 \%$ decrease in area under the force/time curve (AUC) of the endurance test $(P<0.001)$ compared to the control group. Dynamometric parameters were significantly negatively associated with the stage of disease and values of multivariable prediction indexes, and positively associated with the results of 6MWT. In most cases, closer associations were found with AUC than with 6MWT and in the gender-specific groups.

Conclusion: Both hand grip strength and endurance are impaired in COPD patients in comparison with the control group. In particular, AUC could be considered as an attractive option not only to assess exercise capacity but also as a predictive marker with a better prognostic value than 6MWT in COPD patients. This is the first study to observe the dependence of hand grip endurance on combined COPD assessment.

Keywords: dynamometry, muscle strength, muscle endurance, BODE index

\section{Introduction}

Patients with COPD suffer not only from impairment of respiratory function but also often from peripheral muscle dysfunction and atrophy. These are expressed in COPD patients as fatigue and reduction of muscle strength and endurance. Many studies have demonstrated the association of muscle weakness and reduction of endurance with the grade of respiratory impairment, impaired cardiac function and health-related quality of life, the risk of severe COPD exacerbations, and even mortality. ${ }^{1-3}$ As the COPD patient population is not homogeneous, some phenotypes could suffer from loss of muscle more than others (predominantly pulmonary cachexia phenotype). Therefore, testing of muscle strength and endurance should play an important role in clinical practice in COPD patients.
Correspondence: Miloslav Hronek Faculty of Pharmacy, Educational and Research Center of Charles University, Zborovska 2089, Hradec Kralove 50003 Czech Republic

Tel +420 495067254

Fax +420495518002

Email hronek@faf.cuni.cz 
Muscle strength of COPD patients is most commonly determined in the upper limbs, especially as hand grip strength. On the other hand, muscle endurance is more likely tested on the lower limbs by means of simple functional tests such as the 6-minute walk test (6MWT) or sit-to-stand (STS) test. Commonly used in COPD patients is 6MWT. The 6MWT is inexpensive, easy to apply, and known to predict patient mortality. ${ }^{4}$ Although there is a consensus of studies describing the deterioration in the muscular endurance of the lower limbs of COPD patients, the results of the studies are more controversial in the upper limbs. While some studies demonstrated deterioration of upper-limb endurance of COPD patients, ${ }^{5}$ others did not reveal any significant decline. ${ }^{6}$ In addition, some studies found discrepancy in muscle endurance determined on different locations. So in one study, attenuation of lower-limb endurance and preservation of upper-limb endurance could be present at the same time. ${ }^{?}$

The primary goal of this study was comparison of hand grip endurance and strength determined directly by dynamometry between COPD patients and subjects without impairment of respiratory function, referenced to Global Initiative for Chronic Obstructive Lung Disease (GOLD) stage, combined COPD assessment, and multidimensional predictors of mortality (BODE [Body mass index, airflow Obstruction, Dyspnea, Exercise capacity], updated BODE and ADO [Age, Dyspnea, airflow Obstruction] indexes). The secondary goal was to compare hand grip endurance and strength with lower-limb endurance determined by means of 6MWT. To our best knowledge, there has been no previous study determining all these relationships together.

\section{Patients and methods}

\section{Study participants and design of the study}

In this observational study, we compared two study groups. The first study group (control group) consisted of 25 volunteers without respiratory problems: 20 men and 5 women. The second study group (COPD group) consisted of 58 consecutive outpatients with stable COPD (free of acute exacerbation of COPD and/or deterioration of internal comorbidities $>8$ weeks prior to study enrollment): 43 men and 15 women. Detailed basic anthropometric characteristics of both groups are presented in Table 1 .

COPD patients were recruited from the Department of Pneumology, University Hospital Hradec Kralove, Czech Republic (most of them from the Czech multicentric research database of COPD - Registry of the Czech Pneumological and Phthisiological Society). The details concerning inclusion
Table I Basic anthropometric characteristics and functional spirometry

\begin{tabular}{lllll}
\hline Parameter & $\begin{array}{l}\text { Control }_{\text {total }} \\
(\mathbf{n}=\mathbf{2 5})\end{array}$ & $\begin{array}{l}\text { Control }_{\text {male }} \\
(\mathbf{n}=\mathbf{2 0})\end{array}$ & $\begin{array}{l}\text { COPD }_{\text {total }} \\
(\mathbf{n}=\mathbf{5 8})\end{array}$ & $\begin{array}{l}\text { COPD }_{\text {male }} \\
(\mathbf{n}=\mathbf{4 3 )}\end{array}$ \\
\hline Age (years) & $65 \pm 6$ & $66 \pm 6$ & $67 \pm 7$ & $67 \pm 7$ \\
Height (cm) & $174 \pm 7$ & $176 \pm 7$ & $170 \pm 8$ & $173 \pm 7$ \\
Weight (kg) & $88.0 \pm 17.7$ & $91.3 \pm 17.5$ & $81.1 \pm 20.3$ & $87.5 \pm 17.9$ \\
BMI ( $\left(\mathrm{kg} \cdot \mathrm{m}^{-2}\right)$ & $29.0 \pm 5.0$ & $29.6 \pm 5.1$ & $27.9 \pm 6.1$ & $29.1 \pm 5.6$ \\
FFMI $\left(\mathrm{kg} \cdot \mathrm{m}^{-2}\right)$ & $20.5 \pm 3.1$ & $21.4 \pm 2.7$ & $19.7 \pm 3.4$ & $20.9 \pm 2.9$ \\
FEV $(\%$ pv) & $101 \pm 14$ & $101 \pm 13$ & $52 \pm 20^{\mathrm{a}}$ & $53 \pm 20^{\mathrm{a}}$ \\
FVC (\% pv) & $97 \pm 17$ & $97 \pm 15$ & $78 \pm 22^{\mathrm{a}}$ & $77 \pm 21^{\mathrm{a}}$ \\
PEF (\% pv) & $88 \pm 23$ & $90 \pm 23$ & $55 \pm 23^{\mathrm{a}}$ & $58 \pm 25^{\mathrm{a}}$ \\
FEV $/$ FVC & $83 \pm 8$ & $83 \pm 7$ & $51 \pm 13^{\mathrm{a}}$ & $52 \pm 13^{\mathrm{a}}$ \\
\hline
\end{tabular}

Notes: Results are expressed as mean \pm SD. ${ }^{a} t$-Test COPD vs control group $(P \leq 0.05)$.

Abbreviations: BMI, body mass index; FFMI, fat-free mass index; $\mathrm{FEV}_{1} / \mathrm{FVC}$, Tiffeneau index; $\mathrm{FEV}_{1}$, forced expiratory volume in one second; FVC, forced vital capacity of the lungs; PEF, peak expiratory flow; pv, predicted values.

and exclusion criteria and records of a patient history including comorbidities and medications used were described by Novotná et al. ${ }^{8}$ All COPD subjects underwent a comprehensive examination to determine COPD severity and prognostic scales (eg, GOLD stage, combined COPD assessment, BODE, updated BODE and ADO indexes), and exercise tolerance by means of $6 \mathrm{MWT}$.

In all study participants, body composition, basic spirometric parameters, hand grip strength, and endurance were determined. All measurements were taken in the morning after a fast of 12 hours (in COPD patients before commencement of rehabilitation).

The study was reviewed and approved by the Ethical Committee of University Hospital in Hradec Kralove; all subjects gave written informed consent.

\section{COPD severity and prognostic scales}

The BODE index was calculated according to Celli et $\mathrm{al}^{9}$ and the updated BODE $\left({ }_{U} \mathrm{BODE}\right)$ and $\mathrm{ADO}$ indexes according to Puhan et al. ${ }^{10}$ Patients were divided into four grades in line with the GOLD classification according to post-bronchodilator airflow limitation. ${ }^{11}$ Combined COPD assessment was used to distinguish patients to four categories according to risk and level of symptoms. ${ }^{12}$

\section{6-Minute walk test}

The 6MWT was conducted in accordance with guidelines of Czech Pneumological and Phthisiological Society (updated version from 2016) based on the American Thoracic Society/ European Respiratory Society standards. ${ }^{13}$ It was performed indoors, along flat, straight corridor, 30-50 m long. Values of 
6MWT for the control group were calculated using reference equations for healthy adults. ${ }^{14}$

\section{Body composition}

Body weight was measured in underwear to the nearest $0.1 \mathrm{~kg}$ (Tanita Corporation, Tokyo, Japan) and height with a stadiometer to the nearest $0.5 \mathrm{~cm}$. Both were used to calculate the body mass index $\left(\mathrm{kg} \cdot \mathrm{m}^{-2}\right)$. Body composition was determined by means of skin-fold anthropometry, because this method has been proved as appropriate for COPD patients. ${ }^{15}$ The average of the three measurements taken in four standard places (triceps, biceps, subscapular, and suprailiac) using a caliper (Best K-501; Trystom, Olomouc, Czech Republic) was used for further calculations. All measurements were performed by a sole trained examiner. Body density was estimated according to the method of Durnin and Womersley, ${ }^{16}$ and fat mass was calculated with the Siri equation. ${ }^{17}$ Fat-free mass (FFM) was calculated by subtracting the amount of fat mass from body weight. Fat mass and FFM were corrected for height to produce fat mass and FFM index, expressed in $\mathrm{kg} \cdot \mathrm{m}^{-2}$.

\section{Hand grip strength and endurance}

For the hand grip strength and endurance measurement, a Pinch/Grip Analyser (MIE Medical Research Ltd., Leeds, UK) with Clinical Analysis Software (CAS) ${ }^{18}$ was used. Patients were standing with the shoulders adducted, elbows flexed to $90^{\circ}$, and forearms in neutral position.

Maximum strength was assessed on both limbs. Patients were instructed to squeeze the handle as much as possible for 3-5 seconds. The CAS allows visualization of the amplitude distribution during the test. Three repetitions of the test were performed (the break between repetitions was always at least 1 minute). The dominant limb was determined according to the best performance. The results of maximum strength were also corrected for body weight, amount of FFM, and forced vital lung capacity.

The endurance test measures a patient's ability to maintain a constant force within a given range for a duration of time. The target strength value was determined as $50 \% \pm 5 \%$ of maximal strength for each individual patient. The patients were instructed to maintain the force for as long as possible, always keeping within the target range or as close to it as can be managed. The CAS allows patients easy real-time audio-visual control of target range. At the end of the test, the CAS automatically calculates the scored time (the time in which the load was within the target range) and the numerical value of the endurance as the area under the force/time curve
(AUC). The results of AUC were also corrected for body weight, amount of FFM, and forced vital lung capacity.

\section{Statistical analysis}

The acquired data were analyzed using programs GraphPad Prism6 (GraphPad Software, La Jolla, CA, USA) and Excel 2016 (Microsoft, Redmont, WA, USA). All parameters were evaluated by descriptive statistics. Normality of data was assessed by D'Agostino and Pearson omnibus normality test. The unpaired $t$-test, Mann-Whitney $U$-test, or Wilcoxon signed rank test were used for determining differences between COPD and control groups. The ordinary one-way analysis of variance with Tukey's multiple comparisons test or Kruskal-Wallis test were applied to determine differences among the four GOLD stages or groups according to the combined COPD assessment in observed parameters. Spearman's correlation coefficient was used for demonstration of relationships between parameters. Calculation of z-score was used for testing of the difference between two dependent correlations with one variable in common by means of online calculator. ${ }^{19}$ Significance was accepted at $P<0.05$. Results are expressed as mean $\pm \mathrm{SD}$ or median (25th percentile; 75 th percentile).

\section{Results}

\section{Basic anthropometric characteristics}

Basic anthropometric characteristics of the study groups are summarized in Table 1 . The mean value of body mass index $27.9 \pm 6.1$ corresponds to overweight, while the mean value of FFM index corresponds to normal FFM. No significant differences between the study groups were found in any of the basic anthropometric characteristics.

\section{Hand grip strength and endurance}

The results of hand grip testing and 6MWT are summarized in Table 2. We found that patients of the COPD group had a $15 \%$ decrease in maximum strength $(P=0.012)$. When the results were corrected for kilogram of body weight or kilogram of FFM, the maximum strength was comparable between the groups. On the other hand, when the results were corrected for forced vital lung capacity, the COPD group showed a $17 \%$ higher strength than the control group $(P=0.012)$. Correlation analysis revealed that maximum strength was significantly negatively associated with GOLD stage and values of multivariable prediction indexes, and positively associated with results of 6MWT (for details see Table 3 ).

The scored time of endurance test was $\sim 20 \%$ shorter in the COPD group compared with the control group $(P=0.001)$. 
Table 2 Hand grip strength, endurance, and 6MWT

\begin{tabular}{|c|c|c|c|c|}
\hline $\begin{array}{l}\text { Dynamometric } \\
\text { parameters }\end{array}$ & $\begin{array}{l}\text { Control } \\
(n=25)\end{array}$ & $\begin{array}{l}\text { Control }_{\text {male }} \\
(n=20)\end{array}$ & $\begin{array}{l}\text { COPD }_{\text {total }} \\
(n=58)\end{array}$ & $\begin{array}{l}\text { COPD }_{\text {male }} \\
(n=43)\end{array}$ \\
\hline Max grip $(\mathrm{N})$ & $37 I \pm 90$ & $395 \pm 82$ & $316 \pm 88^{a}$ & $342 \pm 80^{a}$ \\
\hline Max grip $\left(\mathrm{N} \cdot \mathrm{kg}^{-1}\right)$ & $4.0(3.6 ; 4.9)$ & $4.3(3.6 ; 5.1)$ & $3.9(3.6 ; 5.1)$ & $3.9(3.3 ; 4.6)$ \\
\hline Max grip $\left(\mathrm{N} \cdot \mathrm{kg} \mathrm{FFM}^{-1}\right)$ & $6.0 \pm 1.1$ & $6.0 \pm 1.2$ & $5.6 \pm 1.4$ & $5.5 \pm 1.4$ \\
\hline Max grip (N.FVC $\left.{ }^{-1}\right)$ & $96(87 ; 114)$ & $96(87 ; 113)$ & $112(96 ; 131)^{a}$ & $112(95 ; 140)^{a}$ \\
\hline Scored time (s) & $104(88 ; 128)$ & $102(80 ; 117)$ & $82(67 ; 100)^{a}$ & $81(68 ; 97)^{\mathrm{a}}$ \\
\hline AUC (thousands) & $18.9(16.0 ; 24.2)$ & $19.1(16.1 ; 24.3)$ & $13.6(\mid 1.2 ; 16.1)^{\mathrm{a}}$ & $13.7(11.7 ; 16.6)^{2}$ \\
\hline $\mathrm{AUC} / \mathrm{kg}$ & $223(198 ; 263)$ & $223(196 ; 256)$ & $176(134 ; 207)^{\mathrm{a}}$ & $166(126 ; 201)^{a}$ \\
\hline AUC/kg FFM & $314(276 ; 367)$ & $304(270 ; 363)$ & $238(182 ; 281)^{\mathrm{a}}$ & $230(180 ; 259)^{\mathrm{a}}$ \\
\hline AUC/FVC (thousands) & $4.7(4.1 ; 5.6)$ & $4.6(4.1 ; 5.3)$ & $4.9(3.8 ; 6.0)$ & $4.9(3.8 ; 5.6)$ \\
\hline 6MWT (m) & $537(484 ; 564)$ & $542(487 ; 569)$ & $390(345 ; 420)^{\mathrm{a}}$ & $420(360 ; 450)^{\mathrm{a}}$ \\
\hline
\end{tabular}

Notes: Results are expressed as mean \pm SD or median (25th percentile; 75 th percentile). ${ }^{\text {a }}$-Test, Mann-Whitney $U$-test, or Wilcoxon signed rank test COPD vs control group $(P \leq 0.05)$. Values of $6 \mathrm{MWT}$ for control group were calculated by using reference equations for healthy adults. ${ }^{14}$

Abbreviations: 6MWT, 6-minute walk test; AUC, area under the force/time curve; FFM, fat-free mass; FVC, forced vital capacity of lungs; Max grip, maximum hand grip strength of dominant arm; Scored time, elapsed time of endurance test in targeted range only.

We found a significant negative association with scored time and combined COPD assessment and positive association with 6MWT. All of them were weaker than associations with maximum strength or AUC.

The AUC for COPD patients was about $28 \%$ lower than for the control group $(P<0.001)$. When the results were

Table 3 Correlation of dynamometric parameters with stage of disease, values of multivariable prediction indexes, and results of 6MWT

\begin{tabular}{|c|c|c|c|c|c|c|}
\hline & GOLD & CCA & BODE & ${ }^{\text {BOODE }}$ & ADO & 6MWT \\
\hline \multicolumn{7}{|c|}{ Max grip (total) } \\
\hline $\mathrm{R}$ & -0.357 & -0.235 & -0.435 & -0.503 & -0.397 & 0.565 \\
\hline$P$ & 0.006 & 0.075 & 0.001 & $<0.00 \mathrm{I}$ & 0.002 & $<0.001$ \\
\hline \multicolumn{7}{|c|}{ Max grip (male) } \\
\hline $\mathrm{R}$ & -0.237 & -0.137 & -0.361 & -0.447 & -0.427 & 0.494 \\
\hline$P$ & 0.126 & 0.381 & 0.017 & 0.003 & 0.004 & 0.001 \\
\hline \multicolumn{7}{|c|}{ AUC (total) } \\
\hline $\mathrm{R}$ & -0.410 & -0.434 & -0.440 & -0.440 & $-0.27 I$ & 0.331 \\
\hline$P$ & 0.001 & 0.001 & 0.001 & 0.001 & 0.036 & 0.011 \\
\hline \multicolumn{7}{|c|}{ AUC (male) } \\
\hline $\mathrm{R}$ & -0.464 & -0.414 & -0.522 & -0.509 & -0.458 & 0.382 \\
\hline$P$ & 0.002 & 0.006 & $<0.001$ & $<0.00 \mathrm{I}$ & 0.002 & 0.011 \\
\hline \multicolumn{7}{|c|}{ 6MWT (total) } \\
\hline $\mathrm{R}$ & -0.398 & -0.314 & $(-0.486)$ & $(-0.585)$ & -0.412 & - \\
\hline$P$ & 0.002 & 0.017 & $(<0.001)$ & $(<0.001)$ & 0.001 & - \\
\hline \multicolumn{7}{|c|}{ 6MWT (male) } \\
\hline $\mathrm{R}$ & -0.417 & -0.293 & $(-0.457)$ & $(-0.547)$ & -0.373 & - \\
\hline$P$ & 0.005 & 0.057 & $(0.002)$ & $(<0.001)$ & 0.014 & - \\
\hline
\end{tabular}

Notes: Values marked red are the highest association for each parameter (column), and bolded values reached statistical significance $(P \leq 0.05)$. Values in parentheses are included for illustrative purposes only (for better orientation), as 6MWT and BODE or BODE are not independent variables.

Abbreviations: 6MWT, 6-minute walk test; ADO, value of ADO index; AUC, area under the force/time curve; BODE, value of BODE index; CCA, combined COPD assessment; GOLD, classification of the Global Initiative for Chronic Obstructive Lung Disease according to post-bronchodilator airflow limitation; Max grip, maximum hand grip strength of dominant arm; $P$, probability values of correlation test; $r$, spearman correlation coefficient; ${ }_{4} B O D E$, value of updated BODE index. corrected for kilogram of body weight or kilogram of FFM, the difference between the groups remained significant. The grouping to quartiles of COPD patients according to the AUC value revealed significant differences among subgroups in GOLD stage $(P=0.024)$, combined COPD assessment ( $P=0.011)$, BODE $(P=0.010)$, uBODE $(P=0.014)$, and ADO $(P=0.040)$ indexes, whereas no differences were found in values of 6MWT. When we compared associations of AUC and 6MWT with stage of disease and values of ADO index, we found closer associations for AUC than 6MWT. Comparing male groups only, the differences between COPD and control groups were almost identical as in the case of groups not divided according to gender.

\section{COPD severity and BODE index}

Comparing COPD groups divided according to GOLD stage, we observed significant differences in maximum strength, AUC, and 6MWT, with worst results in stage 4 (for details, see Table 4). For comparison of values of AUC and GOLD stage, see Figure 1.

Comparing COPD groups according to the combined COPD assessment, we demonstrated significant differences only in AUC, with patients of group D (high risk, more symptoms) having the worst results. For detailed results, see Table 5.

Comparing COPD groups according to the BODE index score, there was a significant decrease in maximum strength and AUC with increasing BODE index score. For detailed results, see Table 6.

\section{Discussion}

The results of our study confirmed previous observations that both hand grip strength and endurance are diminished 
Table 4 Dynamometric parameters and 6MWT in COPD groups divided according to GOLD stage

\begin{tabular}{|c|c|c|c|c|c|c|}
\hline $\begin{array}{l}\text { Dynamometric } \\
\text { parameters }\end{array}$ & $\begin{array}{l}\text { Control } \\
(n=25)\end{array}$ & $\begin{array}{l}\text { GOLD I } \\
(n=7)\end{array}$ & $\begin{array}{l}\text { GOLD } 2 \\
(n=24)\end{array}$ & $\begin{array}{l}\text { GOLD } 3 \\
(n=20)\end{array}$ & $\begin{array}{l}\text { GOLD } 4 \\
(n=7)\end{array}$ & A/K-W \\
\hline Max grip (N) & $37 I \pm 90$ & $375 \pm 96$ & $330 \pm 79$ & $300 \pm 87$ & $255 \pm 82^{a}$ & 0.046 \\
\hline Scored time $(s)$ & $104(88 ; 128)$ & $104(94 ; 123)$ & $82(68 ; 99)^{a}$ & $78(66 ; 90)^{\mathrm{a}}$ & $84(59 ; 122)$ & 0.277 \\
\hline AUC (thousands) & $18.9(16.0 ; 4.2)$ & $18.5(15.5 ; 1.8)$ & $14.0(11.8 ; 16.2)^{\mathrm{a}}$ & $12.1(11.1 ; 13.8)^{\mathrm{a}, \mathrm{b}}$ & II.7 $(9.7 ; \mid 4.0)^{\mathrm{a}, \mathrm{b}}$ & 0.013 \\
\hline $\mathrm{AUC} / \mathrm{kg}$ & $223(198 ; 263)$ & $190(179 ; 260)$ & $162(128 ; 224)^{\mathrm{a}}$ & $170(122 ; 191)^{a}$ & $180(120 ; 197)$ & 0.283 \\
\hline AUC/kg FFM & $314(276 ; 367)$ & $280(225 ; 408)$ & $237(185 ; 290)^{a}$ & $232(176 ; 275)^{\mathrm{a}}$ & $215(158 ; 259)$ & 0.270 \\
\hline 6MWT (m) & $537(484 ; 564)$ & $390(360 ; 450)^{\mathrm{a}}$ & $420(368 ; 450)^{a}$ & $375(320 ; 450)^{a}$ & $300(240 ; 360)^{\mathrm{a}}$ & 0.007 \\
\hline
\end{tabular}

Notes: A/K-W, $P$-value of one-way analysis of variance or Kruskal-Wallis test, bolded values reached statistical significance $(P \leq 0.05)$. Results are expressed as mean $\pm \mathrm{SD}$ or median (25th percentile; 75 th percentile). ${ }^{a}$-Test, Mann-Whitney $U$-test, or Wilcoxon signed rank test vs control group ( $\left.P \leq 0.05\right)$; ${ }^{b} t$-test or Mann-Whitney $U$-test vs GOLD I $(P \leq 0.05)$. Values of 6MWT for the control group were calculated using reference equations for healthy adults. ${ }^{14}$

Abbreviations: 6MWT, 6-minute walk test; AUC, area under the force/time curve; FFM, fat-free mass; GOLD, grade of COPD according to GOLD stage; Max grip, maximum hand grip strength of dominant arm; Scored time, elapsed time of endurance test in targeted range only.

in COPD patients compared with healthy subjects. ${ }^{2,20-22}$ Decreased endurance was possibly caused not only by reduced weight or amount of FFM, but also by muscle dysfunction. This hypothesis is evidenced by the fact that after correction for weight and FFM, there were significant differences between groups in endurance (expressed as AUC), while not in the case of strength, even though there were no significant differences between the groups in weight or amount of FFM. FFM is, therefore, possibly a determinant of maximum hand grip strength, but not endurance. Similar conclusions have been described by Vilaro et al. ${ }^{23}$

According to our knowledge, this is the first study to observe the dependence of hand grip endurance on combined COPD assessment (previously only an association with exacerbations had been determined). It is illustrated by the fact that the lowest strength and endurance were found in the category of combined COPD assessment corresponding to the group of patients with high risk and more symptoms (and

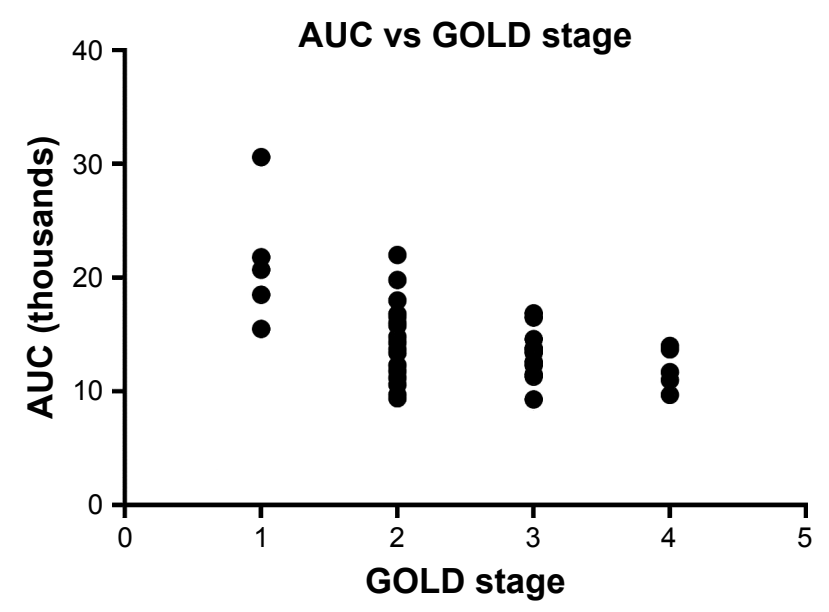

Figure I Comparison of area under the force/time curve with GOLD stage. Abbreviations: AUC, area under the force/time curve; GOLD, classification of the Global Initiative for Chronic Obstructive Lung Disease according to postbronchodilator airflow limitation. highest GOLD stage). We confirmed this also with correlation tests. We revealed a negative association of endurance with category of combined COPD assessment, while an association with strength has not been confirmed. Both strength and endurance were negatively correlated also with GOLD stage. A closer association was found with endurance. Puhan et al studied the association of endurance (determined with STS test) and exacerbations, but they found no significant association. ${ }^{3}$ On the other hand, Vilaró et al found a correlation of global muscle dysfunction with exacerbations. ${ }^{1}$

There have been other studies investigating the correlation of strength and endurance with the BODE index, ${ }^{24,25}$ but very little is known about associations with UBODE and ADO indexes. Puhan et al found that endurance (determined with STS test) predicted 2-year mortality almost as well as the ADO index. ${ }^{3}$ It was also demonstrated that STS is also associated with 5 -year mortality. ${ }^{26}$ Analogous to clinical stage, we proved the dependence of BODE index on both hand grip strength and endurance. The lowest strength and endurance were found in the subgroup of patients with the highest BODE score. Correlation test revealed a significant association of strength and endurance not only with BODE, but also with the $\mathrm{UBODE}$ and $\mathrm{ADO}$ indexes. The association with the $\mathrm{ADO}$ index is especially remarkable, because unlike the BODE index, the ADO index does not contain a measure of muscle mass or function.

The closest correlations of all the dynamometric parameters were found in the case of AUC, especially in the male-only population. The advantage of this endurance parameter over the others could be that besides endurance, it also includes a strength component. Moreover, we have found that AUC is more closely associated with the most tested parameters than $6 \mathrm{MWT}$, which is very often used in clinical practice. However, testing the differences between correlation coefficients did not achieve any statistical 
Table 5 Dynamometric parameters and 6MWT in COPD groups divided according to combined COPD assessment

\begin{tabular}{|c|c|c|c|c|c|}
\hline $\begin{array}{l}\text { Dynamometric } \\
\text { parameters }\end{array}$ & $\begin{array}{l}\text { Control } \\
(n=25)\end{array}$ & $\begin{array}{l}\text { Group A } \\
(n=3)\end{array}$ & $\begin{array}{l}\text { Group B } \\
(n=24)\end{array}$ & $\begin{array}{l}\text { Group D } \\
(n=31)\end{array}$ & $A / K-W$ \\
\hline Max grip $(\mathrm{N})$ & $37 I \pm 90$ & $369 \pm 124$ & $332 \pm 82$ & $298 \pm 88^{a}$ & 0.210 \\
\hline Scored time (s) & $104(88 ; 128)$ & I $23(83 ;$ । 47$)$ & $91(69 ; 108)$ & $77(62 ; 89)^{\mathrm{a}}$ & 0.075 \\
\hline AUC (thousands) & $18.9(16.0 ; 24.2)$ & $18.4(14.2 ; 30.6)$ & $15.4(|| .8 ; 7.1)^{\mathrm{a}, \mathrm{b}}$ & $11.9(10.9 ; 13.8)^{\mathrm{a}, \mathrm{b}}$ & 0.004 \\
\hline $\mathrm{AUC} / \mathrm{kg}$ & $223(198 ; 263)$ & $185(136 ; 311)$ & $176(137 ; 236)$ & $170(121 ; 191)^{\mathrm{a}}$ & 0.454 \\
\hline AUC/kg FFM & $314(276 ; 367)$ & $280(229 ; 450)$ & $245(190 ; 330)$ & $228(175 ; 264)^{a}$ & 0.172 \\
\hline 6MWT (m) & $537(484 ; 564)$ & $420(390 ; 420)$ & $410(360 ; 450)^{\mathrm{a}}$ & $360(300 ; 420)^{\mathrm{a}}$ & 0.057 \\
\hline
\end{tabular}

Notes: A/K-W, $P$-value of one-way analysis of variance or Kruskal-Wallis test, bolded values reached statistical significance $(P \leq 0.05)$. Results are expressed as mean \pm SD or median (25th percentile; 75th percentile). ${ }^{a} t$-Test, Mann-Whitney $U$-test, or Wilcoxon signed rank test vs control group ( $\left.P \leq 0.05\right)$; ${ }^{b} t$-test or Mann-Whitney $U$-test vs Group A $(P \leq 0.05)$. Values of $6 \mathrm{MWT}$ for the control group were calculated using reference equations for healthy adults. ${ }^{14}$

Abbreviations: 6MWT, 6-minute walk test; AUC, area under the force/time curve; FFM, fat-free mass; Max grip, maximum hand grip strength of dominant arm; Scored time, elapsed time of endurance test in targeted range only.

Table 6 Dynamometric parameters and 6MWT in COPD groups divided according to BODE index score

\begin{tabular}{|c|c|c|c|c|c|}
\hline $\begin{array}{l}\text { Dynamometric } \\
\text { parameters }\end{array}$ & $\begin{array}{l}\text { Control } \\
(n=25)\end{array}$ & $\begin{array}{l}\text { BODE 0-2 } \\
(n=29)\end{array}$ & $\begin{array}{l}\text { BODE 3-4 } \\
(\mathrm{n}=20)\end{array}$ & $\begin{array}{l}\text { BODE 5-10 } \\
(n=9)\end{array}$ & A/K-W \\
\hline $\operatorname{Max}$ grip $(\mathrm{N})$ & $37 I \pm 90$ & $342 \pm 82$ & $313 \pm 83$ & $240 \pm 80^{a, b}$ & 0.007 \\
\hline AUC (thousands) & $18.9(16.0 ; 24.2)$ & $15.5(11.8 ; 17.6)^{\mathrm{a}}$ & I2.I (II.I; I3.8) & II. $2(8.5 ; 14.3)^{\mathrm{a}}$ & 0.012 \\
\hline 6MWT (m) & $537(484 ; 564)$ & $420(360 ; 450)^{\mathrm{a}}$ & $395(353 ; 420)^{\mathrm{a}}$ & $270(210 ; 300)^{a, b}$ & $<0.001$ \\
\hline
\end{tabular}

Notes: A/K-W, $P$-value of one-way analysis of variance or Kruskal-Wallis test, bolded values reached statistical significance $(P \leq 0.05)$. Results are expressed as mean $\pm \mathrm{SD}$

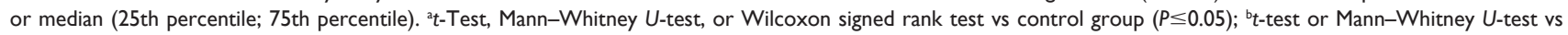
BODE 0-2 ( $P \leq 0.05)$. Values of 6MWT for the control group were calculated using reference equations for healthy adults. ${ }^{14}$

Abbreviations: AUC, area under the force/time curve; Max grip, maximum hand grip strength of dominant arm.

significance, probably due to limited sample size. In addition, AUC was the only dynamometric parameter with significant differences among groups of patients divided according to combined COPD assessment, whereas we found no differences among these groups in the results of 6MWT. Also, the fact that grouping to quartiles of COPD patients according to AUC value revealed no significant differences in values of 6MWT confirms that AUC and 6MWT are not interchangeable parameters. A similar conclusion has been published regarding cycle endurance test and 6MWT. ${ }^{27}$ On the other hand, special equipment (a dynamometer) is needed for determination of AUC. Although its use is very simple and examination alone is very quick and does not cost anything, nevertheless, acquisition of this device requires a one-time investment (about 3,000 US dollars). AUC could thus be considered as an attractive option to assess exercise capacity in COPD patients.

A limitation of this study is the low number of participants in some studied subgroups, and also we have not examined associations directly with mortality. Another limitation is that for the control group, we calculated 6MWT by reference to equations.

In conclusion, we have confirmed that both hand grip strength and endurance are impaired in COPD patients. AUC in particular could be considered as an attractive option not only to assess exercise capacity but also as a predictive marker with a better prognostic value than 6MWT in COPD patients in both clinical practice and research. Further studies with larger sample size will be required to evaluate the predictive and prognostic value of AUC. This is the first study to observe the dependence of hand grip endurance on combined COPD assessment.

\section{Acknowledgments}

This work was not supported by sponsors: the Faculty of Pharmacy (SVV/2017/260417), MH CZ - DRO (UHHK, 00179906), and PROGRES Q42 are gratefully acknowledged. The authors are grateful to Ian $\mathrm{McColl} \mathrm{MD}, \mathrm{PhD}$, for assistance with preparation of the manuscript.

\section{Author contributions}

MK served as principal investigator, had full access to all of the data in the study, and takes responsibility for the integrity of the data and the accuracy of the data analysis; MK, VK, $\mathrm{ZZ}$, and MH contributed to study design; MK, VJ, AP, VK, and $\mathrm{MH}$ contributed to data collection; $\mathrm{MK}, \mathrm{VJ}, \mathrm{AP}, \mathrm{VK}$, $\mathrm{ZZ}$, and $\mathrm{MH}$ contributed to data analysis; MK contributed to statistical analysis; MK, VJ, AP, VK, ZZ, and MH contributed to the writing of the manuscript; $\mathrm{ZZ}$ and $\mathrm{MH}$ supervised the study. All authors contributed toward data analysis, drafting and revising the paper and agree to be accountable for all aspects of the work. 


\section{Disclosure}

The authors report no conflicts of interest in this work.

\section{References}

1. Vilaró J, Ramirez-Sarmiento A, Martínez-Llorens JM, et al. Global muscle dysfunction as a risk factor of readmission to hospital due to COPD exacerbations. Respir Med. 2010;104(12):1896-1902.

2. Cortopassi F, Divo M, Pinto-Plata V, Celli B. Resting handgrip force and impaired cardiac function at rest and during exercise in COPD patients. Respir Med. 2011;105(5):748-754.

3. Puhan MA, Siebeling L, Zoller M, Muggensturm P, Ter Riet G. Simple functional performance tests and mortality in COPD. Eur Respir $J$. 2013;42(4):956-963.

4. Pinto-Plata VM, Cote C, Cabral H, Taylor J, Celli BR. The 6-min walk distance: change over time and value as a predictor of survival in severe COPD. Eur Respir J. 2004;23(1):28-33.

5. Shah S, Nahar P, Vaidya S, Salvi S. Upper limb muscle strength \& endurance in chronic obstructive pulmonary disease. Indian J Med Res. 2013;138(4):492-496.

6. Clark CJ, Cochrane LM, Mackay E, Paton B. Skeletal muscle strength and endurance in patients with mild COPD and the effects of weight training. Eur Respir J. 2000;15(1):92-97.

7. Franssen FM, Broekhuizen R, Janssen PP, Wouters EF, Schols AM. Limb muscle dysfunction in COPD: effects of muscle wasting and exercise training. Med Sci Sports Exerc. 2005;37(1):2-9.

8. Novotna B, Koblizek V, Zatloukal J, et al. Czech multicenter research database of severe COPD. Int J Chron Obstruct Pulmon Dis. 2014;9: 1265-1274.

9. Celli BR, Cote CG, Marin JM, et al. The body-mass index, airflow obstruction, dyspnea, and exercise capacity index in chronic obstructive pulmonary disease. $N$ Engl J Med. 2004;350(10):1005-1012.

10. Puhan MA, Garcia-Aymerich J, Frey M, et al. Expansion of the prognostic assessment of patients with chronic obstructive pulmonary disease: the updated BODE index and the ADO index. Lancet. 2009; 374(9691):704-711.

11. Rabe KF, Hurd S, Anzueto A, et al; Global Initiative for Chronic Obstructive Lung Disease. Global strategy for the diagnosis, management, and prevention of chronic obstructive pulmonary disease: GOLD executive summary. Am J Respir Crit Care Med. 2007;176(6):532-555.

12. Vestbo J, Hurd SS, Agustí AG, et al. Global strategy for the diagnosis, management, and prevention of chronic obstructive pulmonary disease: GOLD executive summary. Am J Respir Crit Care Med. 2013; 187(4):347-365.

13. Chlumsky J. Standard pro šestiminutový test chůzí. Available from: http://www.pneumologie.cz/upload/1480163894.pdf. Accessed September 25, 2017.
14. Enright PL, Sherrill DL. Reference equations for the six-minute walk in healthy adults. Am J Respir Crit Care Med. 1998;158(5 Pt 1): 1384-1387.

15. Hronek M, Kovarik M, Aimova P, et al. Skinfold anthropometry-the accurate method for fat free mass measurement in COPD. COPD. 2013; 10(5):597-603.

16. Durnin JV, Womersley J. Body fat assessed from total body density and its estimation from skinfold thickness: measurements on 481 men and women aged from 16 to 72 years. Br J Nutr. 1974;32(1):77-97.

17. Siri WE. Body composition from fluid space and density. In Brozek J, Hanschel A. Techniques For Measuring Body Composition. Washington, DC: National Academy of Sciences; 1961:223-244.

18. Clinical Analysis Software for MIE's Digital Analyser Products. Available from: https://www.mie-uk.com/software/wincas/index.html. September 25, 2017.

19. Lee IA, Preacher KJ. Calculation for the test of the difference between two dependent correlations with one variable in common [Computer software]. 2013. Available from: http://quantpsy.org. Accessed September 25, 2017.

20. Malaguti C, Nery LE, Dal Corso S, et al. Scaling skeletal muscle function to mass in patients with moderate-to-severe COPD. Eur J Appl Physiol. 2006;98(5):482-488.

21. van den Borst B, Slot IG, Hellwig VA, et al. Loss of quadriceps muscle oxidative phenotype and decreased endurance in patients with mild-tomoderate COPD. J Appl Physiol (1985). 2013;114(9):1319-1328.

22. Hodonska J, Neumannova K, Svoboda Z, et al. Incremental shuttle walk test as an indicator of decreased exercise tolerance in patients with chronic obstructive pulmonary disease. Acta Gymnica. 2016;46(3):117-121.

23. Vilaro J, Rabinovich R, Gonzalez-deSuso JM, et al. Clinical assessment of peripheral muscle function in patients with chronic obstructive pulmonary disease. Am J Phys Med Rehabil. 2009;88(1):39-46.

24. Regueiro EM, Di Lorenzo VA, Basso RP, Pessoa BV, Jamami M, Costa D. Relationship of BODE Index to functional tests in chronic obstructive pulmonary disease. Clinics (Sao Paulo). 2009;64(10):983-988.

25. Inal-Ince D, Savci S, Saglam M, et al. Fatigue and multidimensional disease severity in chronic obstructive pulmonary disease. Multidiscip Respir Med. 2010;5(3):162-167.

26. Crook S, Frei A, Ter Riet G, Puhan MA. Prediction of long-term clinical outcomes using simple functional exercise performance tests in patients with COPD: a 5-year prospective cohort study. Respir Res. 2017;18(1):112.

27. Andrianopoulos V, Wagers SS, Groenen MT, et al; CIRO + Rehabilitation Network. Characteristics and determinants of endurance cycle ergometry and six-minute walk distance in patients with COPD. BMC Pulm Med. 2014;14:97.
International Journal of COPD

\section{Publish your work in this journal}

The International Journal of COPD is an international, peer-reviewed journal of therapeutics and pharmacology focusing on concise rapid reporting of clinical studies and reviews in COPD. Special focus is given to the pathophysiological processes underlying the disease, intervention programs, patient focused education, and self management protocols.

\section{Dovepress}

This journal is indexed on PubMed Central, MedLine and CAS. The manuscript management system is completely online and includes a very quick and fair peer-review system, which is all easy to use. Visit $\mathrm{http}: / / \mathrm{www}$. dovepress.com/testimonials.php to read real quotes from published authors. 